\title{
RESPIRATORY STUDIES WITH TRICHLOROETHYLENE
}

\author{
Howard Malchy, B.SC., and James Parkhouse, M.A., M.D., F.F.A.R.C.S., D.A.
}

STUDIES concerning the recovery of inhaled trichloroethylene in expired air have been carried out during exposure to low (subanaesthetic) concentrations in man. ${ }^{1,2}$ Experimentally, the respiratory intake and output of trichloroethylene have been studied in rats $^{3}$ and many studies of the metabolism of the drug have been carried out, for example those of Barrett and Johnston, ${ }^{4}$ Butler, ${ }^{5}$ and Soucek and Valchova. ${ }^{6}$ Attempts have been made to administer known concentrations of trichloroethylene, in the anaesthetic range, to human subjects, and to measure arterial and venous blood concentrations and the urinary concentration of metabolites. $^{7,8}$ Helliwell and Hutton ${ }^{9}$ compared trichloroethylene concentrations in the maternal and foetal blood of sheep.

\section{METHOD}

Patients were studied during clinical anaesthesia with nitrous oxide, oxygen, and supplemerital intravenous agents when required. When conditions were stabilized and the investigation was ready to begin, a known inspired concentration of trichloroethylene was introduced into the nitrous-oxide-oxygen mixture from a "tritec" vaporizer which had previously been checked for accuracy in the laboratory. A non-rebreathing system was employed, using a large diameter low-resistance non-return respiratory valve assembly (Warren Collins $\uparrow$ ).

A sample port immediately before the inspiratory valve permitted sampling and analysis of the inspired trichloroethylene concentration. Expired gas from the valve assembly was passed into an airtight metal container, of approximately four litres capacity, which was connected directly to the valve assembly by means of a short metal union. Mixing of expired gas occurred in this chamber, and a sample port permitted regular sampling and analysis of expired gas.

The distal end of the container was connected by corrugated tubing to a laboratory type dry gas meter so that the expired gas volume could be continuously and cumulatively measured. The inspired minute volume was measured in some cases by including a Wright respirometer in the system. Readings did not always correspond with those of the dry gas meter on the expiratory side, and laboratory comparison of the two meters confirmed this discrepancy. It was not possible to use a dry gas meter on the inspiratory side because this would have absorbed a variable amount of trichloroethylene vapor. It was felt, however, that the dry gas meter was considerably more accurate than the Wright respirometer and in most cases measurements were accordingly confined to expired gas volumes.

Because of the absorption of trichloroethylene by corrugated rubber tubing, the

-Department of Anaesthetics, University of Manitoba.

tWarren E. Collins Inc., catalogue \#P306. 
"tritec" was connected to the patient by way of a specially constructed reservoir bag and tube of nylon.

After this experimental exposure to trichloroethylene, the length of which was determined by the operative procedure, the "tritec" was turned off and removed from the circuit, together with the rubber connecting hose on the outlet side. The nylon reservoir bag and tubing were replaced by a fresh trichloroethylene-free nylon tube and bag. Sampling showed that with these arrangements the inspired trichloroethylene concentration rapidly became negligible, being of the order of 0.05 per cent during the first ten minutes after discontinuation and falling thereafter to the order of 0.001 per cent.

Sampling and analysis of expired gas continued until the conclusion of surgery. In practice, exhalation of trichloroethylene was monitored for between 14 and 62 minutes after the end of exposure; by this time the expired concentrations were very low.

All patients were intubated throughout the period of the experiment, and studies were confined to spontaneously breathing patients. All patients had undergone the usual preoperative fast, and an intravenous infusion of 5 per cent dextrose was maintained at a slow rate.

Samples were collected in gastight $50 \mathrm{ml}$. all-glass syringes fitted with metal two-way stopcocks. Before drawing a sample from the expiratory chamber the syringe was connected to the sample port, filled, and rapidly emptied into the chamber again, several times, to promote mixing. Gas meter readings for expiratory volume determinations were taken periodically, and expiratory gas samples were collected midway between these readings. Thus, the total exhalation of trichloroethylene was divided, for experimental purposes, into a series of time periods, with an expired concentration reading for the mid-point of each period. During times of rapid change, for example at the start of administration and immediately after exposure, samples and readings were taken every minute; at other stages two- and four-minute intervals were used.

Gas samples were analysed by gas chromatography, using a gas sample valve. This device enabled a known, constant volume of the gas sample to be introduced onto the column at atmospheric pressure; it gave consistent and repeatable results. A Varian Aerograph Model 1520-B Chromatograph was used, with an 8 foot long, $1 \frac{1}{18}$ inch diameter Carbowax column on $20 \mathrm{M} 60 / 80$ Chromosorb W, at a temperature of $125^{\circ} \mathrm{C}$, using a carrier gas flow of $22.5 \mathrm{ml} / \mathrm{min}$ nitrogen. In these circumstances, the retention time for trichloroethylene was $2 / 2$ minutes. A flame ionization detector was used. Concentrations were estimated from peak areas by means of a disc integrator and duo-digital counter. Figure 1 shows a series of peaks obtained from successive injections of samples from the same vapour mixture: the mean peak area is $364.6 \pm \mathrm{sD} 2.5$.

A Rayleigh interferometer (Carl Zeiss) was calibrated for trichloroethylene from a specially prepared cylinder of 3.12 per cent vapour in air (Matheson Co.). This is an absolute instrument which, once calibrated, will not vary from day to day providing suitable corrections are made for temperature and barometric pressure. Each day during the investigation split samples of a trichloroethylene/ air mixture drawn from a specially calibrated EMO inhaler were analysed by 
MALCHY \& PARKHOUSE: RESPIRATORY STUDIES WITH TRICHLOROETHYLENE

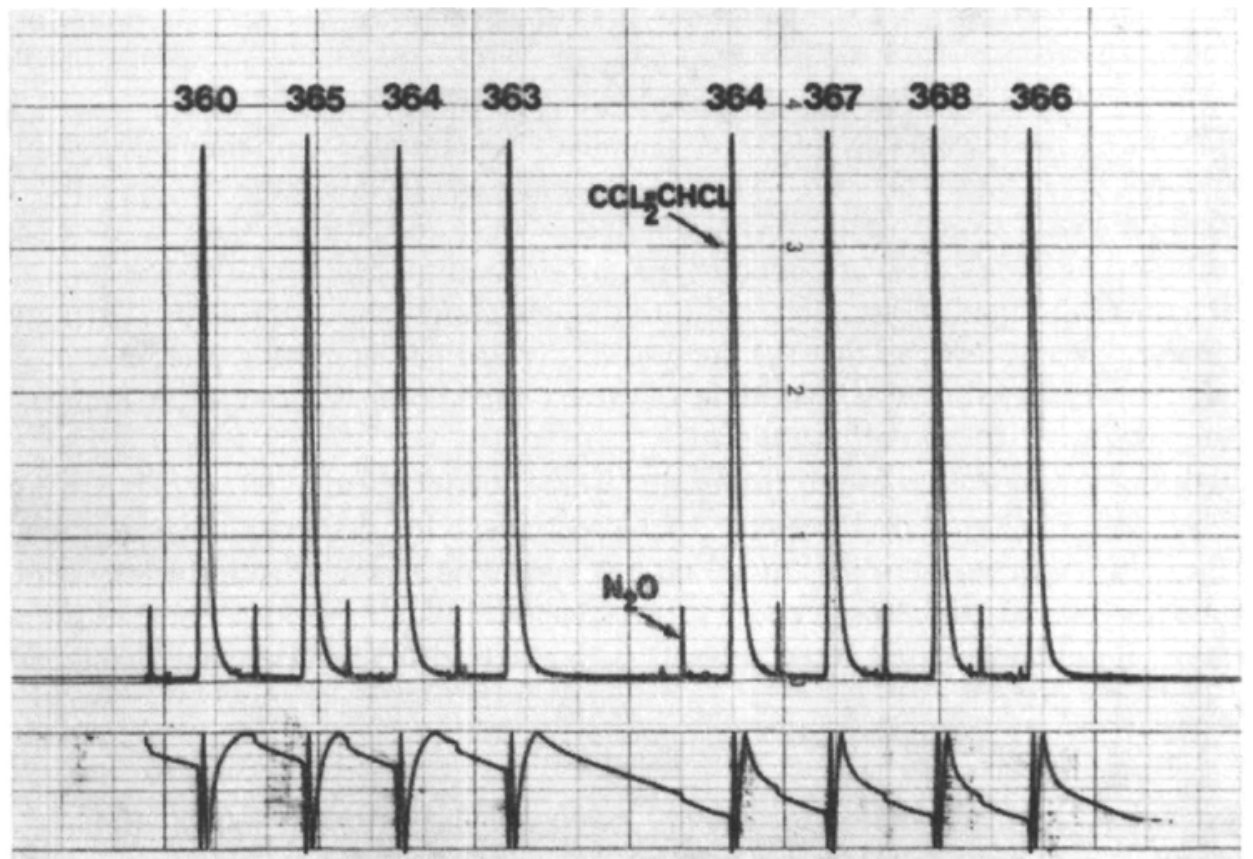

FIGURE 1. Successive peaks obtained from injections of samples from the same vapour mixture containing trichloroethylene. Numbers above peaks are peak areas; small peaks represent nitrous oxide (see text).

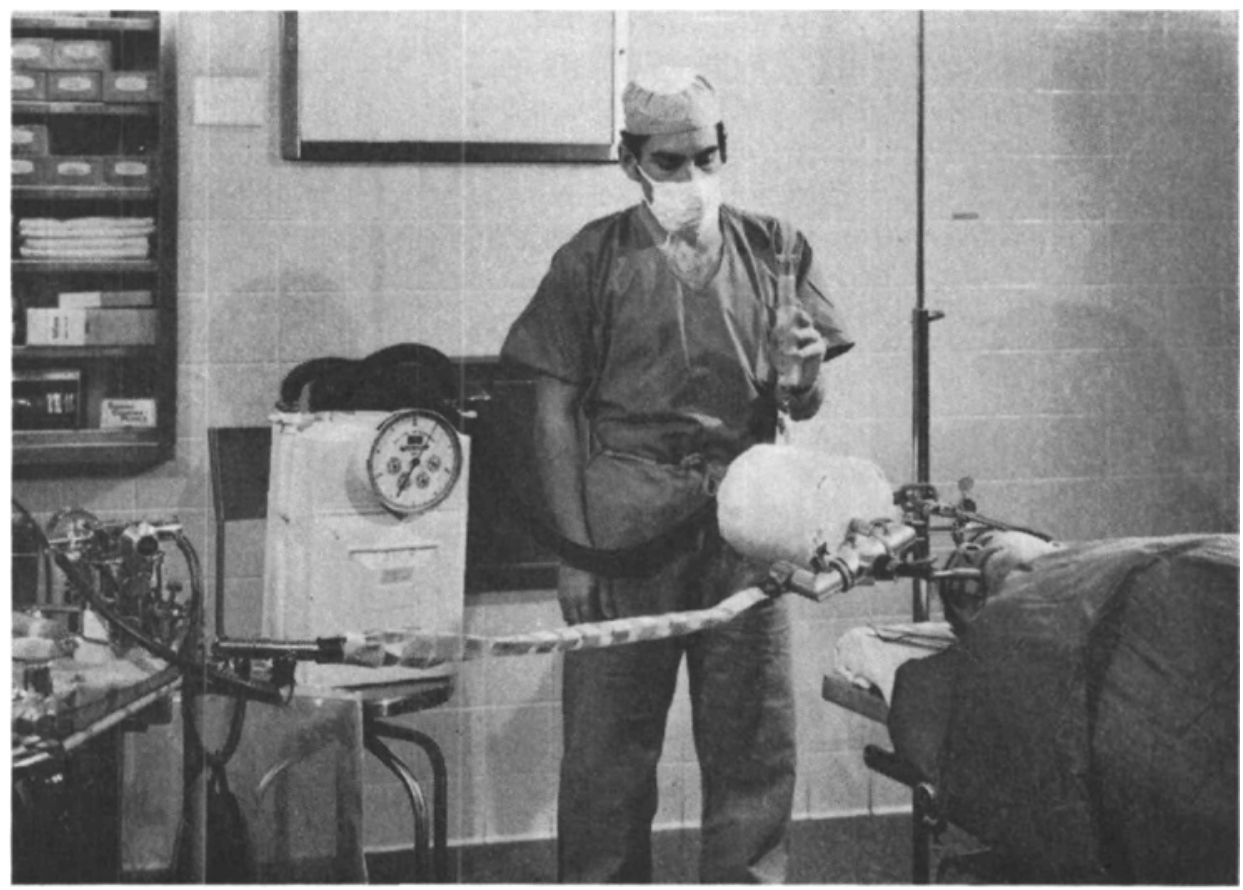

Figure 2. Experimental arrangements described in text. 
interferometry and gas chromatography and thus, from the known calibration of the interferometer, and with appropriate corrections for temperature and barometric pressure, the gas chromatograph was calibrated.

Inspired gases were dry, and were sampled at operating room temperature and ambient barometric pressure. They were analysed at laboratory temperature. Expired gases were presumably saturated with water vapour and were also collected and measured at operating room temperature and ambient barometric pressure. All samples were injected into the gas sample valve through a calcium chloride drying tube, so that the analysis of expired gas samples represented dry gas percentage; this was also at laboratory temperature. The experimental arrangements are illustrated in Figure 2.

With the method described, results were obtained from 36 patients who received 0.5 per cent or 1 per cent trichloroethylene for various periods of time. Three experiments were performed on the inhalation of lower concentrations, in the range of 0.1 to 0.3 per cent, two in a volunteer and one in a patient. Data were also obtained from three patients who received 0.5 per cent halothane for 16 minutes each.

\section{Results}

It was recognized that many factors might influence the amount of trichloroethylene retained and metabolized in the body, and hence the percentage recovery. It was felt that two of the most important of these factors might be the inspired concentration and the duration of exposure. Cases were therefore studied in groups, of varying lengths of exposure from 15 to 60 minutes, and within these groups there were exposures to 0.5 per cent and 1 per cent trichloroethylene. An analysis of the details of these 36 cases is given in Table I. This table also shows, for each inspired concentration and each duration of exposure, the means and their standard errors for the following parameters (where $t_{1}=$ duration of exposure, $t_{2}=$ duration of experiment ).

Column 10, total percentage recovery of inhaled trichloroethylene:

$$
\frac{\sum_{0}^{t_{2}} \dot{V} \bar{F}_{E}}{\sum_{0}^{t_{1}} \dot{V} \bar{F}_{I}} \times 100
$$

Column 11, percentage of inhaled trichloroethylene absorbed:

$$
\frac{\sum_{0}^{t_{1}} \dot{V} \bar{F}_{I}-\sum_{0}^{t_{1}} \dot{V} \vec{F}_{E}}{\sum_{0}^{t_{1}} \dot{V} \bar{F}_{I}} \times 100 .
$$

Column 12, percentage recovery of trichloroethylene absorbed:

$$
\frac{\sum_{\mathrm{I}_{1}}^{\mathrm{t}_{2}} \dot{\mathrm{V}} \overline{\mathrm{F}}_{\mathrm{E}}}{\sum_{0}^{\mathrm{t}_{1}} \dot{\mathrm{V}} \overline{\mathrm{F}} \mathrm{I}-\sum_{0}^{\mathrm{t}_{1}} \dot{\mathrm{V}} \overline{\mathrm{F} E}} \times 100 .
$$

A typical case is illustrated in Figure 3. 


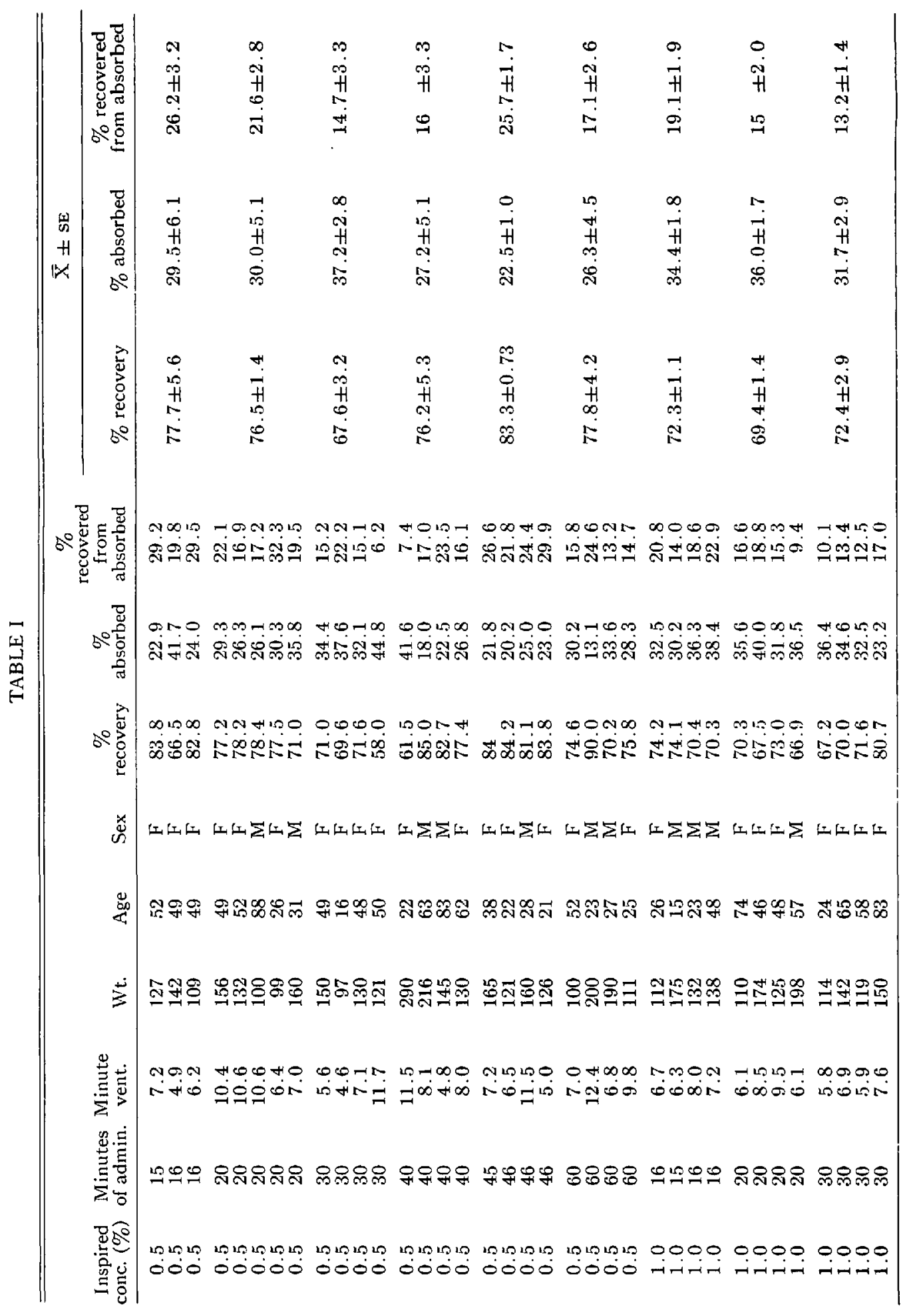




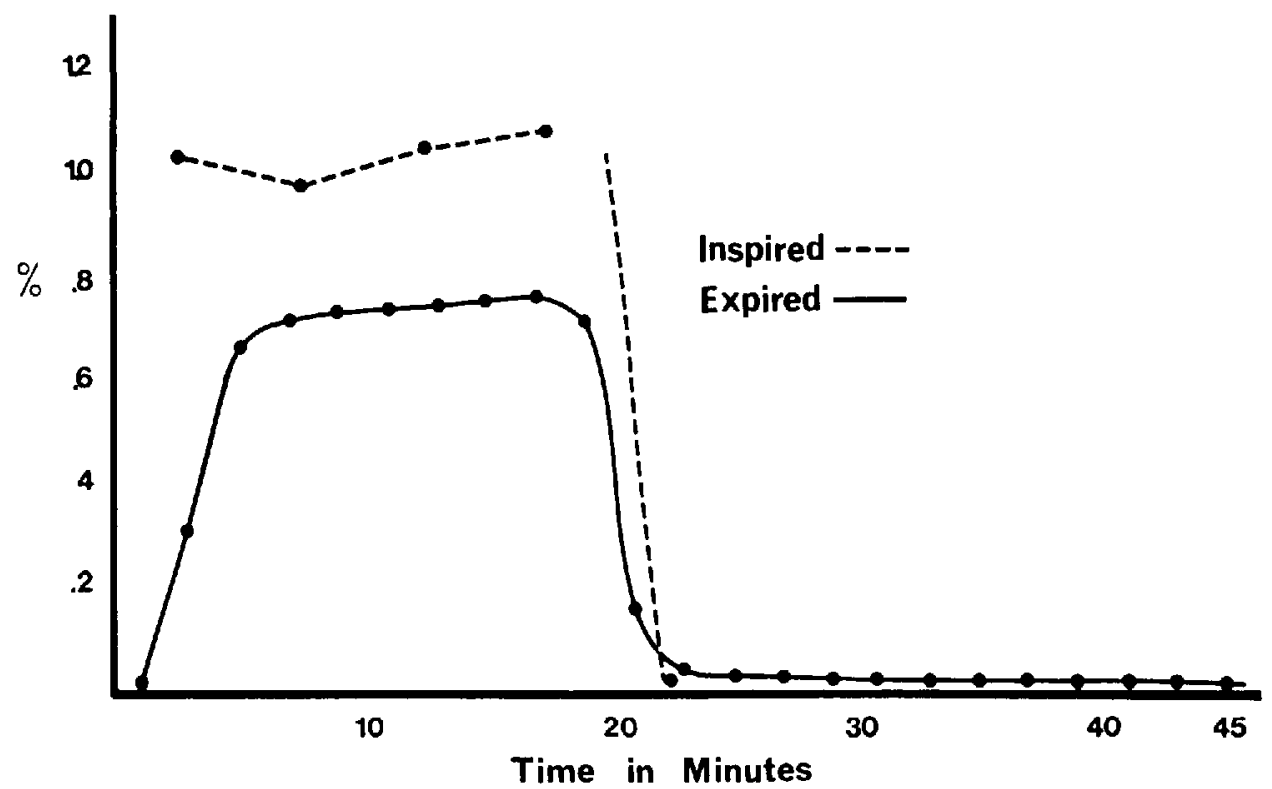

Ficure 3. Inspired and expired trichloroethylene concentrations during and after the clinical administration of a nominal 1 per cent trichloroethylene for 20 minutes.

The behaviour of the "tritec" vaporizer was fairly consistent, although sampling of the inspired mixture at ten-minute intervals disclosed some fluctuations. In occasional cases there was a fairly marked transient fall in inspired concentration which seemed to be related to change in ventilation; it is unlikely that this was an experimental error in analysis since it was mirrored by a fall in expired concentration. When marked fluctuations in inspired concentration were observed, the data were rejected.

A comparison was made of 0.5 per cent administration and 1 per cent administration on the basis of the total amount of trichloroethylene exhaled, as a percentage of the total amount inhaled (total percentage recovery). Approximately half the patients showed a recovery of over 75 per cent, and this was accordingly taken as a dividing line; a chi-square analysis shows a statistically significant difference, the percentage recovery of unchanged trichloroethylene being lower after 1 per cent administration than after 0.5 per cent $(p<0.025)$. But in view of the fact that the administration of 1 per cent trichloroethylene was limited to 30 minutes, while some of the 0.5 per cent administrations extended over 60 minutes (see below), a further comparison was made in which the only patients included were those receiving trichloroethylene for 30 minutes or less. Here there was no significant difference, although only 24 cases were available for comparison.

Figure 4 shows the mean percentages of total recovery, with the standard errors of the means, for the groups of patients who received 0.5 per cent trichloroethylene for varying periods of time. The lowest percentage recovery was noted after 30 minutes of exposure, higher recoveries apparently being obtained with longer exposures. Although there was considerable variation between individuals, as evidenced by the standard errors of the means, and although the number of 


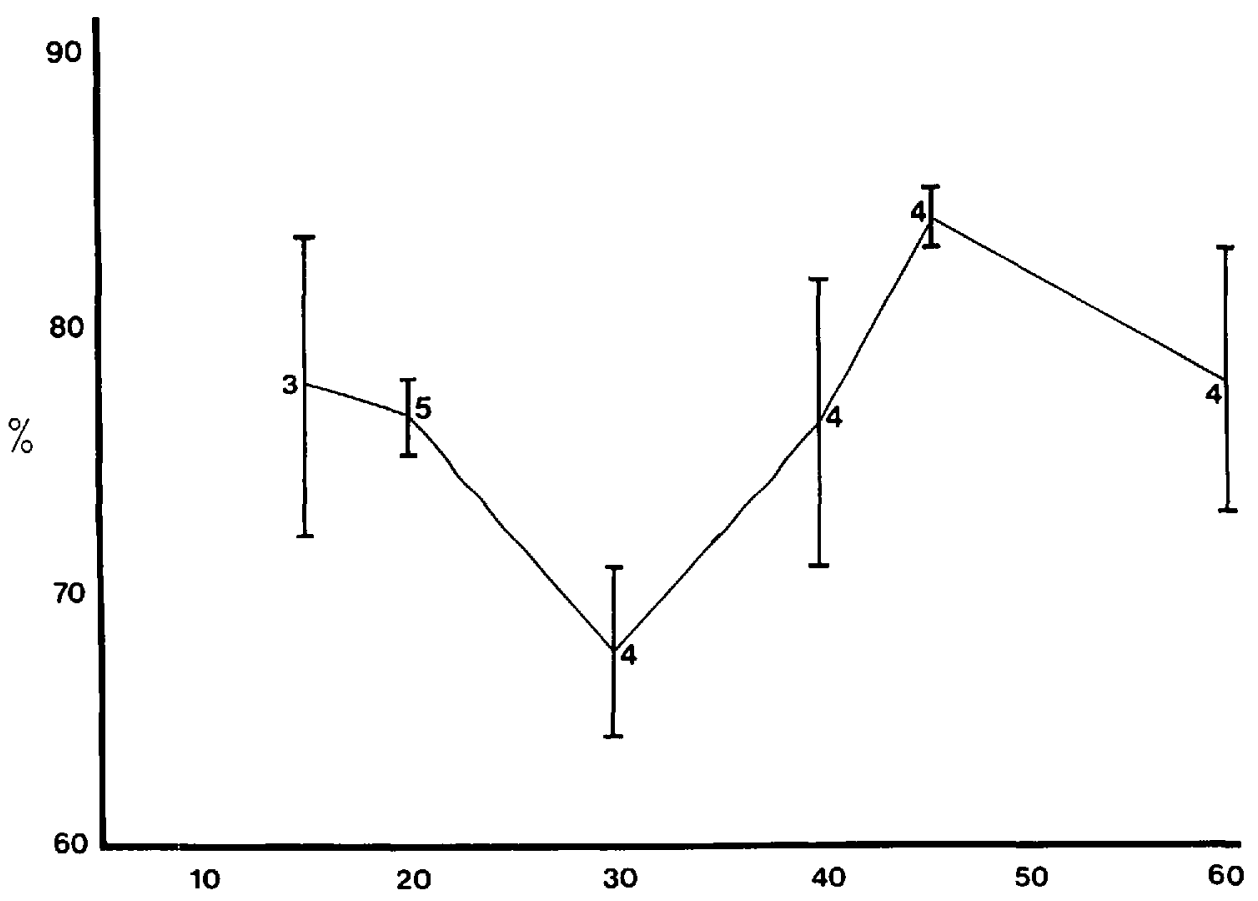

Figure 4. Mean percentages of total recovery of trichloroethylene, with standard errors of the means, for administration of 0.5 per cent. Numbers beside points indicate number of patients in each group. The horizontal axis indicates duration of administration in minutes (see text).

cases in each group was small, the differences in recovery rate between 20 minutes and 30 minutes of administration, and between 30 minutes and 45 minutes, were significant. The comparable results for 1 per cent administration showed a fall in percentage recovery from 16 minutes of administration (72.3\%) to 20 minutes administration $(69.4 \%$ ), the mean percentage recovery for 30 minutes being again higher $(72.4 \%)$. For these 1 per cent data, however, none of the differences was statistically significant.

Statistical analysis revealed no significant influence of age, body weight, or mean minute volume.

Low concentrations of trichloroethylene, in the range of 0.1 to 0.3 per cent, were administered to a healthy volunteer subject on two occasions in the laboratory, and to one patient during anaesthesia. Each of these exposures was for 16 minutes, and the procedure was the same as for the experiments reported above.

In the experimental subject the percentage recovery of inhaled trichloroethylene was 82.3 per cent on one occasion and 76.5 per cent on the other. In this latter case, however, there was a small loss of expired trichloroethylene due to slipping of the mouthpiece at the end of exposure. In the anaesthetized patient, recovery was 80.7 per cent. The mean recovery for these three exposures was thus 79.8 per cent, which compares to a mean of 77.7 per cent for the same length of exposure to 0.5 per cent trichloroethylene and 72.3 per cent for the same length of exposure to 1 per cent. 
In three anaesthetized patients the experiment was reproduced with the introduction of 0.5 per cent halothane instead of trichloroethylene, for 16 minutes. The percentage recovery of inhaled halothane ranged from 73.9 to 86.5 per cent, with a mean of 80.5 per cent for the three cases.

\section{Discussion}

Various methods are available for the comparison of inspired and expired quantities of an inhalation anaesthetic agent. A known concentration of the agent can be prepared in a large bag, and the inhaled volume of this can be measured. Likewise, the expired air can be collected in suitable bags, over appropriate periods of time, and these can then be analysed and measured for volume. We made preliminary studies with a number of bags and found most materials to be unsuitable; rubber, latex, neoprene, canvas (the conventional Douglas bag), and PVC were all found to be freely permeable to trichloroethylene. The only suitable material readily available was nylon, and a number of bags were constructed from large rolls of nylon film. It proved possible to make gastight bags of this nature which would retain trichloroethylene, and some studies were performed in the laboratory in this manner on volunteers. For clinical investigation, however, it is difficult to prepare a sufficiently large volume of gas to permit the careful study of a reasonably prolonged exposure. Furthermore, although concentrations can be measured accurately in this way there is likely to be an error in the measurement of volume; inspired volumes cannot easily be measured without the risk of trichloroethylene uptake, and if expired gas is collected in bags there is a risk of volume loss during the changeover from one bag to another and the precise measurement of the gas content of the bags is more difficult than the continuous use of a dry gas meter on the expired side.

Continuous sampling of inspired and end-tidal trichloroethylene concentrations is possible with an infrared analyser. Suitable apparatus was not available when these studies began, and although a cell and detector for trichloroethylene were later obtained we have some reservations about the speed of response of this instrument with trichloroethylene vapour. Continuous sampling of mixed expired trichloroethylene concentration is possible in this way, but this has no advantage over gas chromatography. The freezing out of volatile agents from expired gas has also been used in studies of other agents.

Studies were restricted to spontaneous respiration, in order to avoid the complications of gas leakage from the system during raised inspiratory pressure, pressure effects on the output of the "tritec" vaporizer, and errors due to blowthrough or rebreathing with the available non-return valves for controlled ventilation. Furthermore, the fact that no ventilator was available which would not absorb trichloroethylene vapour would have meant that controlled ventilation must be carried out by hand, using a nylon reservoir bag, in which case it would have been difficult to maintain a constant rate and tidal volume.

\section{Sources of error}

An investigation of this kind is subject to experimental error for a variety of reasons. Inspired concentration is liable to vary, even with a calibrated quantita- 
tive vaporizer. Various devices were tested for administering trichloroethylene and the "tritec" proved the most suitable and reliable. Inspired samples were taken at intervals of ten minutes or less in each experiment, and the inspired amount of trichloroethylene was calculated as the respiratory volume, over the time period concerned, multiplied by the inspired concentration at the mid-point of the time period. This does not rule out the possibility of transient fluctuations; the effect of these on the total calculated input would probably be small, unless a transient fall coincided with a concentration reading, in which case substantial underestimation would result.

Inspired gas volume was deduced in these experiments from expired gas measurements. Expired gas was saturated with water vapour at room temperature, and its volume would have had to be converted to a dry gas volume in order to obtain a "true" inspired volume. A small correction for the respiratory exchange ratio would then have had to be made, for strict accuracy. In these studies it was felt that the error introduced by neglecting $R$ would be negligible in proportion to other errors, and this was done. Wet and dry gas volumes are further discussed below. As much care was taken as possible, in each experiment, to ensure that there was no leakage in the system at any point.

The inspired amount of trichloroethylene was derived from the inspired concentration and the inspired volume. There remains the problem of residual trichloroethylene from the apparatus, inhaled after the supposed termination of exposure. The experiments were arranged in such a way as to reduce this factor to a minimum, and for the purpose of calculation it has been assumed that no trichloroethylene was inhaled after the "tritec" was removed from the system. The small amounts which were afterwards detected in inspiratory samples almost certainly originated from the rubber disc valves at the mouth. In calculating the percentage of trichloroethylene absorbed during the course of administration, and in calculating the percentage of this absorbed amount which is recovered in the expired air after exposure, it is clearly reasonable to regard the administration as having finished completely when the vaporizer is removed. In calculating total percentage recovery, however, by subtracting all the trichloroethylene exhaled from all the trichloroethylene inhaled, it would be slightly more accurate to include in the inspired quantity the traces inhaled after exposure had "ended." In the results presented, as stated above, inspired amounts were calculated up to the moment when the "tritec" was removed from the system.

Leakage in the non-return valve system and blowing back of expired gas into the inspiratory limb are possible sources of error. With controlled ventilation, the blow-across of inspired gases may vitiate the expired sample. Only spontaneous breathing was used for these studies, and the valve assembly, carefully tested in the laboratory before experiments began, proved to be virtually free from leak and blow-back.

The small uptake of trichloroethylene by the rubber components of the valve assembly and its subsequent release into the passing gas stream have been mentioned above. These were the only rubber parts that it was impossible to eliminate from the system. This source of error was ignored.

Expired gas volume was measured at room temperature, saturated with water vapour. Expired concentration was measured dry, having passed through calcium 
chloride before entering the gas chromatograph. To obtain a true expired amount of trichloroethylene, therefore, the measured expired dry gas concentration for each time period should be multiplied by the dry gas volume for the corresponding period. However, the calculations in this experiment involved the subtraction of an inspired amount of trichloroethylene from an expired amount. Since both inspired volume (see above) and expired volume were taken from the same gas meter reading, and since both inspired and expired trichloroethylene concentrations were measured dry, no corrections were in fact applied to either inspired or expired gas volumes. This should be borne in mind in interpreting the results presented. If true inspired or expired amounts had been required, rather than merely the difference between them, they would have had to be derived from corrected gas volumes.

Estimation of the expired amount of trichloroethylene depends on a number of factors in addition to those mentioned above. With regard to sampling technique, the gas loss and overall error from syringes was regarded as negligible, since it was shown that when a $50 \mathrm{ml}$ syringe was charged with a sample, delay in analysis did not materially affect the repeatability of results.

The use of a mixing chamber on the expiratory side, while facilitating mixing of expired gases, raises the obvious possibility of a time lag. Preliminary studies on mixing were carried out by using an infrared $\mathrm{CO}_{2}$ analyser. Figure 5 shows

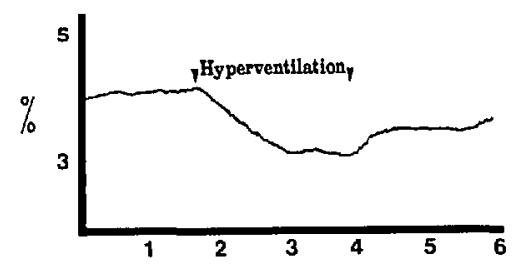

Ficure 5. Results of sampling from expiratory mixing chamber with infrared $\mathrm{CO}_{2}$ analyser during spontaneous breathing in a normal subject. Carbon dioxide percentage on vertical axis; time in minutes on horizontal axis. The mixing of expired gas during respiratory cycles is evident, and the response to hyperventilation is shown (see text).

that when a normal subject expired through the mixing chamber there was a negligible respiratory swing in $\mathrm{CO}_{2}$ concentration within the box; hyperventilation was followed by a fairly prompt change in $\mathrm{CO}_{2}$ concentration within the chamber. Further laboratory experiments were carried out by passing a flow of $10 \mathrm{~L} / \mathrm{min}$ nitrous oxide and oxygen from a standard anaesthetic machine through a nylon tube to the expiratory chamber. Trichloroethylene was then introduced from the "tritec" vaporizer and samples were taken simultaneously from the inlet end of the nylon tube and the chamber. Figure 6 shows the chromatographic peaks thus obtained: the "inspired" concentration fell slightly with time and was closely followed by the chamber concentration; reduction of the "inspired" concentration from 1 per cent to 0.5 per cent resulted in a corresponding fall in 
chamber concentration within two to three minutes. Raising the "inspired" concentration again to 1 per cent resulted in a comparable rise in chamber concentration with about the same time lag. For this test, samples were drawn from the chamber in the same manner as for the experiments described, and the representativeness of a sample taken in this way can be deduced from the evidence presented.

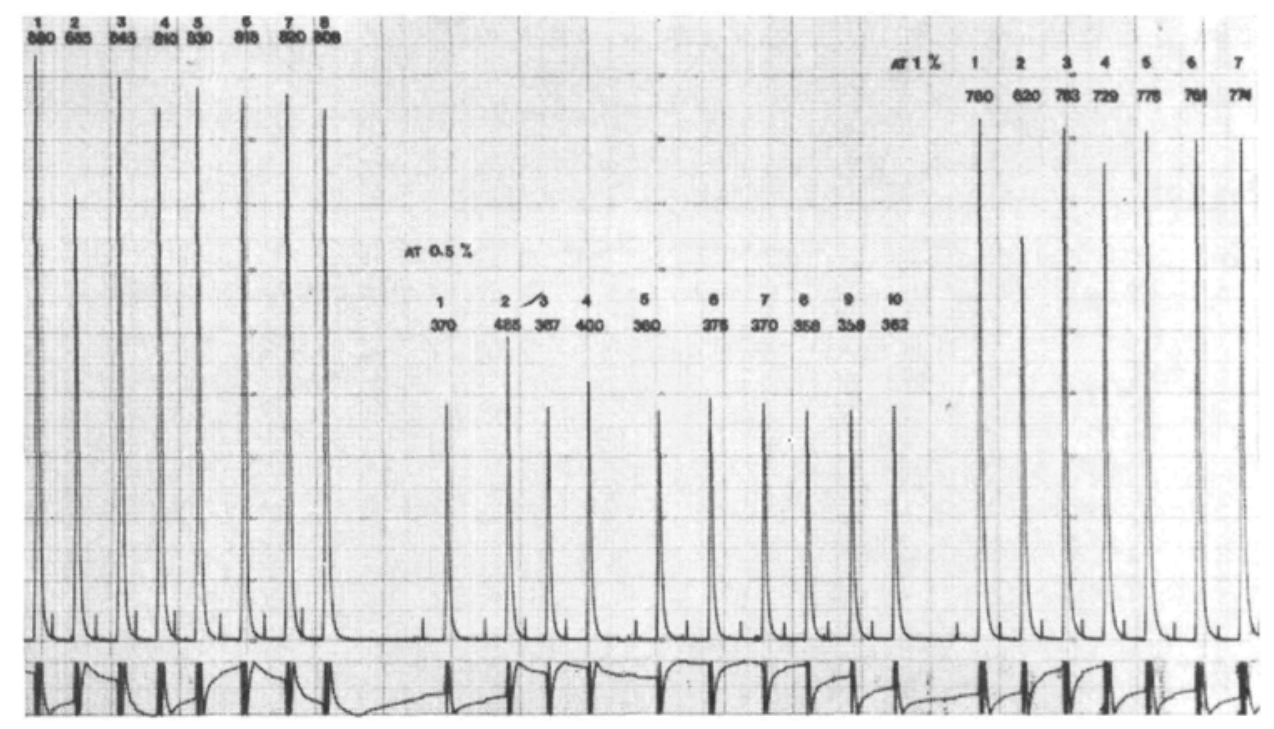

Figure 6. Chromatographic peaks from laboratory test of expiratory chamber time-lag, described in text. Odd-numbered peaks represent "inspired" concentrations, showing a slight fall with time, followed by a reduction from 1 to 0.5 per cent, followed by a return to 1 per cent and a further slight fall with time. Even-numbered peaks show concentrations from the chamber, in samples drawn at the same moment as those analysed in the immediately preceding "inspiratory" peaks. For example, peaks 5 and 6 represent samples taken at the same moment. Samples were taken at one minute intervals; the chamber concentration is seen to approximate to the "inspired" concentration in two to three minutes (see text).

The expired amount of trichloroethylene must in some way be calculated from the data obtained. The two ways of doing this are to plot the expired concentrations as measured at various times, join the points with the curve of best fit, and calculate the area under the curve; or to take each expired concentration as the average for the gas volume in the time period concerned and calculate the total expired amount as the sum of a number of rectangular areas obtained in this way. The latter method was used in calculating the results presented in this paper. Figures 7 and 8 show two representative washout curves, from a 20 minute administration and a 60 minute administration, from which it can be seen that there is a rapid initial phase followed by a long exponential washout. The deviation of the points from a straight line is not to be attributed entirely to experimental error, but rather to random variations in minute volume. Figures 9 and 10 show the washout curves for the same two cases plotted on a linear scale and compared with the rectangular areas obtained by calculating output from mean concentration multiplied by time. It is apparent that with the exception 


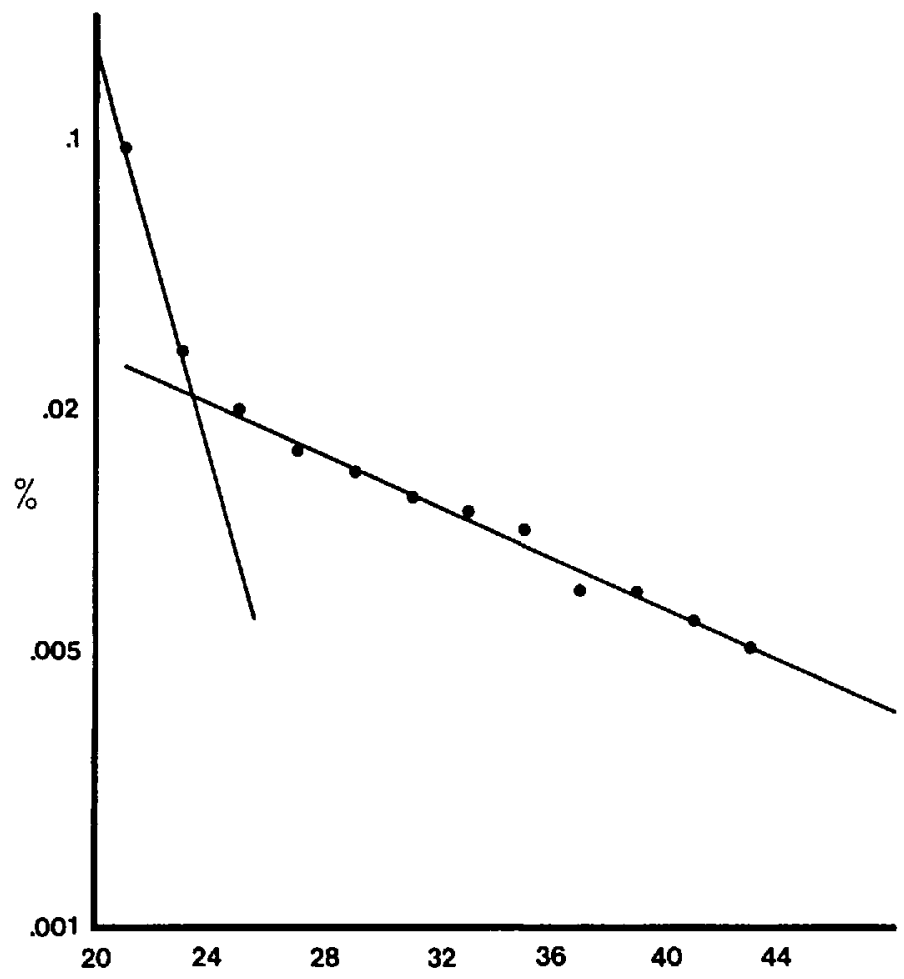

Figure 7. Expired trichloroethylene concentrations plotted logarithmically against time in minutes (horizontal axis) to show exponential washout after a 20 minute administration of 0.5 per cent trichloroethylene (see text).

of the first two minutes of washout the difference between the two methods of calculation is small.

During the first two minutes of washout the expired trichloroethylene concentration changes very rapidly, and an average mixed expired concentration can hardly be said to exist during this period. The "buffering" effect of the expiratory mixing chamber would tend to minimize error during this phase, particularly if output is estimated by the "rectangular" method of calculation. We found this error hard to estimate from first principles, and therefore a further laboratory experiment was performed: a gas flow of $6 \mathrm{~L} / \mathrm{min}$ was passed through a nylon tube into the chamber, then through a Wright respirometer into a nylon bag of 70 litres capacity. Volume readings were taken at one minute intervals and samples were drawn from the chamber midway between consecutive readings. At one minute from the start, 1 per cent trichloroethylene was introduced; at five minutes this was reduced to 0.5 per cent and at nine minutes it was turned off. Gas flow was stopped at twelve minutes, and a final volume meter reading was taken. It was now assumed that all the gas and all the trichloroethylene which had entered the nylon bag had passed through the chamber. Two calculations of the amount of trichloroethylene were made. Firstly, the concentration in the nylon bag was determined and multiplied by the gas volume in 


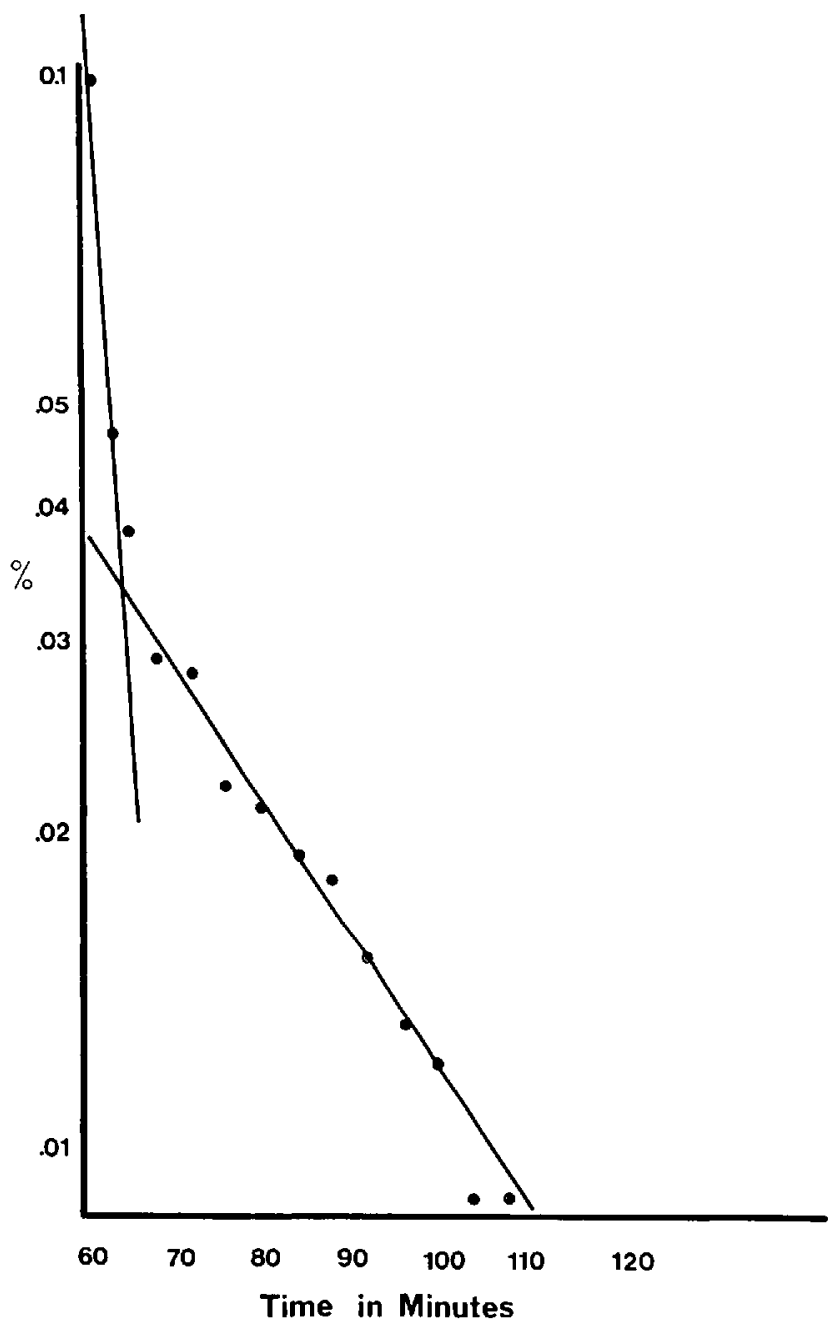

Figure 8. Expired trichloroethylene concentrations plotted logarithmically against time in minutes (horizontal axis) to show exponential washout after a 60 minute administration of 0.5 per cent trichloroethylene (see text).

the bag. Secondly, the concentrations in samples drawn from the chamber were multiplied by the volumes of gas flow for the corresponding time periods. This test represented a rough imitation of the clinical experiments, in that the chamber was exposed first to a trichloroethylene-free gas flow, then to differing concentrations of trichloroethylene; finally, washout from the chamber was followed for some time, but not until the last traces of trichloroethylene had gone. Calculations showed that in this test the total amount of trichloroethylene estimated from the chamber was 92.8 per cent of the amount in the nylon bag at the conclusion of the last time period.

Figures 9 and 10 also give an indication of the amount of trichloroethylene 


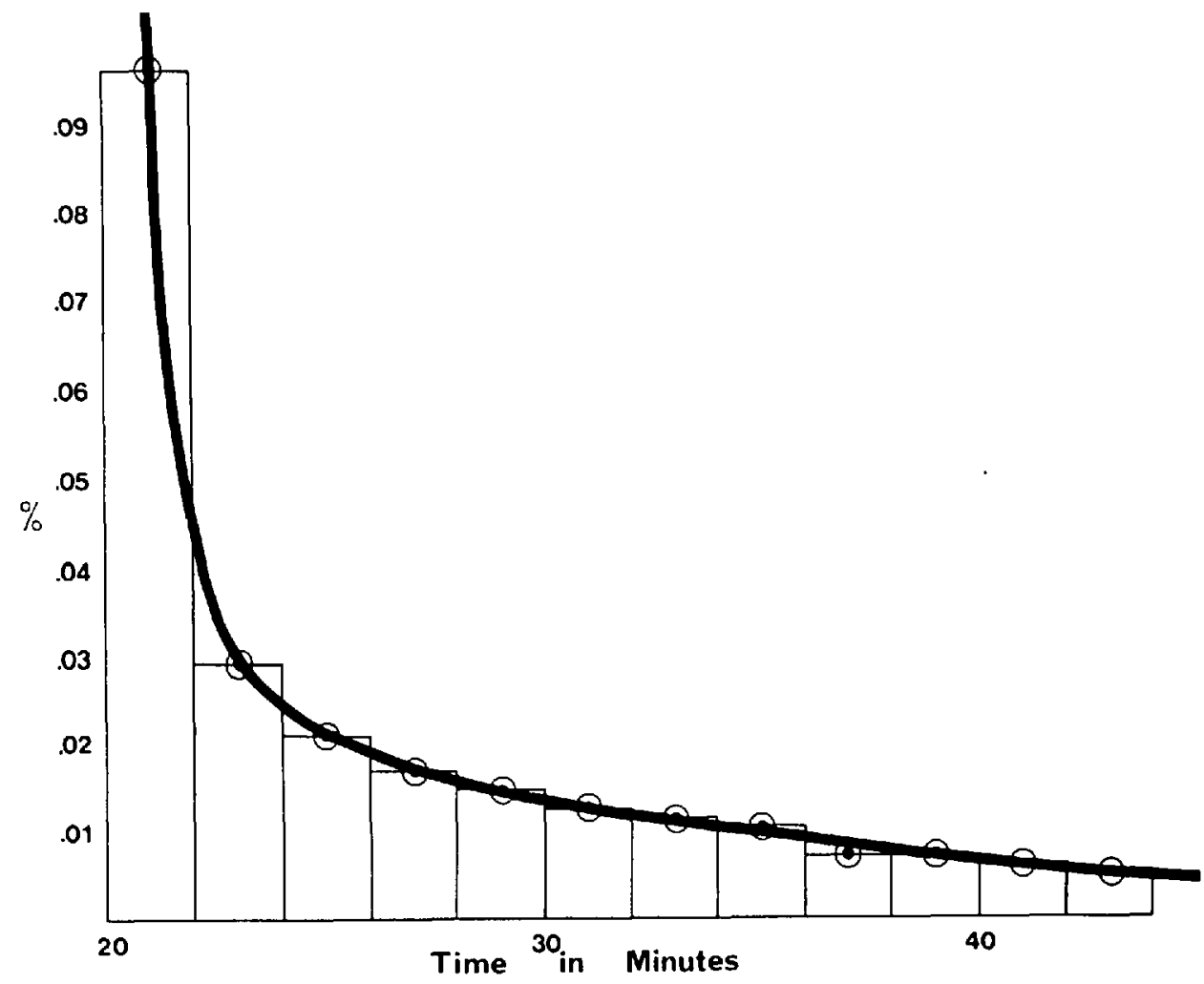

Ficure 9. Expired trichloroethylene concentrations plotted linearly against time in minutes to show relationship of washout curve to average concentrations for each time-period (see text). Twenty minute administration of 0.5 per cent trichloroethylene.

excretion which was missed in these experiments through failure to follow washout for a prolonged period of time. The decision to do this was deliberate, since at the conclusion of surgery the patients were extubated and ventilation often became irregular and variable in volume. These and other complicating factors would probably have made the pursuit of the final traces of trichloroethylene too inaccurate to be worthwhile. Inspection of Figures 9 and 10 would suggest, from extrapolation, that about an additional 10 per cent of the estimated amount of trichloroethlyene washout would have resulted from following excretion to virtual finality. This refers, of course, to an experimental loss of 10 per cent of the trichloroethylene exhaled after exposure was concluded; as a percentage of the total amount of trichloroethylene exhaled during and after the administration the tail would represent a very much smaller amount, and would thus introduce a relatively small error into the calculation of total percentage recovery. These experimental limitations should be borne in mind in interpreting the results presented.

\section{RÉSUMÉ}

Nous avons étudié l'absorption et l'élimination du trichlorethylène donné à 0.5 et 1 pour cent durant des périodes variables chez 36 malades anesthésiés. Comme 


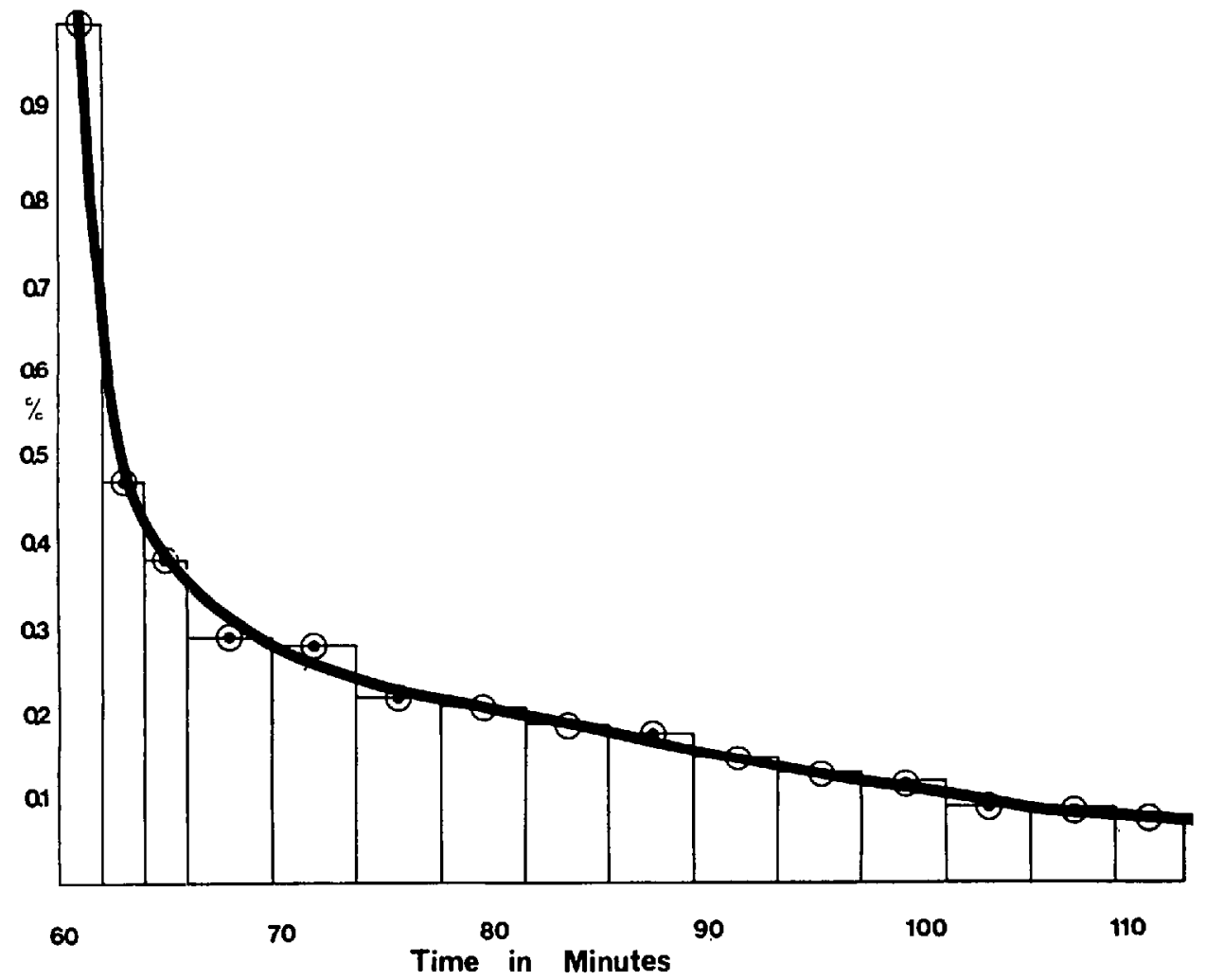

FIGURE 10. Expired trichloroethylene concentrations plotted linearly against time in minutes to show relationship of washout curve to average concentrations for each time-period (see text). Sixty minute administration of 0.5 per cent trichloroethylene.

comparaison nous avons fait des études avec des concentrations plus faibles et avec de l'halothane. A l'aide de chromatographie, nous avons mesuré la concentration de trichlorethylène dans l'air inspiré et dans l'air expiré et nous avons mesuré les volumes de gaz expirés au cours de l'administration et après l'administration. Nos résultats nous permettent de dire que la plupart des facteurs comme l'âge, le sexe, le poids ne semblent pas influencer la quantité de trichlorethylène retenu et métabolisé dans l'organisme. Le facteur le plus important à ce point de vue semble être la durée de l'administration. Chez les trois malades étudiés en somme, la vitesse du réveil pour le chlorethylène a été légèrement inférieure à celle de l'halothane. Nous avons discuté les limites expérimentales d'une recherche de ce genre.

\section{ACKNOWLEDGMENTS}

We should like to acknowledge the co-operation of the surgeons and anaesthetists of the Winnipeg General Hospital. Mr. Wayne Pucci gave invaluable technical assistance. The work was supported by grants from the Medical Research Council of Canada. 


\section{REFERENCES}

1. Teisinger, J. Maximum Allowable Concentrations of Trichloroethylene in Air. Proc. 13th Internat. Congr. Occup. Health. 987 (1960).

2. Bartoničer, V. Metabolism and Excretion of Trichloroethylene after Inhalation by Human Subjects. Brit. J. Indust. Med. 19: 134 (1962).

3. Forssman, S. \& Holmouisr, C. E. The Relationship between Inhaled and Exhaled Trichloroethylene and Trichloracetic Acid Excreted in the Urine of Rats Exposed to Trichloroethylene. Acta Pharmacol. \& Toxicol. 9: 235 (1953).

4. Barnetr, H. M. \& Johnstone, J. H. The Fate of Trichloroethylene in the Organism. J. Biol. Chem. 127: 765 (1939).

5. Butler, T. C. Metabolic Transformation of Trilene. J. Pharmacol. $97: 84$ (1949).

6. SouceK, B. \& Vlachova, D. Excretion of Trichloroethylene Metabolites in Human Urine. Brit. J. Indust. Med. 17: 60 (1960).

7. Powell, J. F. Trichloroethylene: Absorption, Elimination and Metabolism. Brit. J. Indust. Med. 2: 142 (1945).

8. Clayton, J. I. \& Pankhouse, J. Blood Trichloroethylene Concentrations during anaesthesia under Controlled Conditions in Man. Brit. J. Anaesth. 34: 141 (1962)

9. Helliwell, P. J. \& Hutron, A. M. Trichloroethylene Anaesthesia. Anaesthesia. $5: 4$ (1950). 